\title{
Treatment Efficacy in Vertebrobasilar Transient Ischemic Attacks Presenting as Isolated Vertigo: A Retrospective Case Study
}

\author{
Lea Pollak \\ Department of Neurology, Assaf Harofeh Medical Center, Tzrifin, Israel \\ Email: Lea.pollak@gmail.com
}

Received August 10, 2011; revised November 21, 2011; accepted December 7, 2011

\begin{abstract}
Background: Vertigo without other neurological symptoms is usually not supposed to be due to a vascular cause. However, hypoperfusion of the anterior cerebellar artery can lead to ischemia of the vestibular labyrinth and/or vestibular nuclei in the pontomedullary region whereas hypoperfusion of the posterior cerebellar artery can cause ischemia of the vestibulocerebellum, all resulting in isolated vertigo. Methods: We retrospectively reviewed the clinical records of patients with vertebrobasilar ischemic attacks referred to our outpatient dizziness clinic during the years 1999-2009. Patients who presented only with vertigo (+/- vomiting and unsteadiness) were selected. Their clinical data, findings and treatment responses were recorded. Results: Amongst about one hundred patients with vertebrobasilar TIA we found 24 patients with monosymptomatic presentation. Their mean age was 67.3 years, fifteen were men. In most of the patients the vertigo attacsk were multiple and lasted from minutes to hours. All but four patients had at least one vascular risk factor at the time of presentation, among them 13 had multiple vascular risk factors. Seven patients had evidence of chronic ischemic changes on brain CT or MRI. Aspirin (100 - $325 \mathrm{mg} /$ die) was started in 15 patients. Three patients were started on clopidogrel ( $75 \mathrm{mg} / \mathrm{die}$ ) because of aspirin intolerance and two patients on warfarin due to atrial fibrillation. In two patients who were treated with aspirin prior to their vertigo attack, clopidogrel or dipyridamol were added. The mean time period from first attack to treatment initiation was 5.2 months. The mean follow up period was 27.4 months. In 18 patients the attacks have completely resolved after treatment initiation. Three patients had further vertigo attacks despite treatment. Two patients with vertigo episodes where a vascular etiology was not suspected, developed later an ischemic stroke in the vertebrobasilar territory (anterior cerebellar artery and vertebral artery infarct). Conclusions: The differential diagnosis of a vertigo attack presenting in a monosymptomatic form should include vertebrobasilar TIA, especially in individuals with vascular risk factors. In view of lack of a specific test for establishing the diagnosis antiplatelets should be administered on empirical grounds since early administration of therapy can abolish further attacks and prevent a vertebrobasilar stroke. Warfarin should be preserved for patients with cardiac conditions that warrant antiocoagulation for stroke prevention.
\end{abstract}

Keywords: Vertigo; TIA

\section{Introduction}

Vertigo attacks can occur in an isolated form or with other neurological symptoms such as diplopia, dysphagia, numbness, incoordination or paresis. The accompanying symptoms may appear simultaneously with the vertigo, or at another time [1].

Vertigo without other neurological symptoms or signs is usually due to a disorder of the peripheral vestibular system, especially if hearing symptoms are also present [1$3]$. The differential diagnosis of recurrent isolated vertigo episodes is challenging and includes many nosological entities such as vestibular migraine, vestibular paroxysmia, incipient Meniere's syndrome or perilymphatic fis- tula. It has been shown that isolated vertigo, in the form of single or repeated attacks, can be a first presentation of an impending stroke in the vertebrobasilar territory [4-7].

Vertigo due to a TIA was claimed to be of abrupt onset, brief duration and of less than six weeks duration [5]. Hypoperfusion of distinct central or peripheral anatomical structures in the vertebrobasilar territory can lead to isolated vertigo. Firstly, hypoperfusion in the anterior cerebellar artery may cause ischemia of the vestibular labyrinth and vertigo. The diagnosis is easy if auditory and brainstem symptoms, which result from ischemia of the cochlear labyrinth or the pontomedullar region supplied by same artery, are present, but can be difficult if the patient presents only with vestibular symptoms. Secondly, 
hypoperfusion of the posterior cerebellar artery that leads to ischemia of the vestibulocerebellum can also present with vertigo in the absence of other brainstem signs. The clue to the topographical diagnosis is the finding of a direction-changing nystagmus, subtle oculomotor disturbances, such as abnormal smooth pursuit, or severe gait ataxia. Finally, hypoperfusion in the territory of the vertebral artery resulting in a lateral medullary infarct, can be announced by vertigo attacks [1,8-10].

A vascular cause of isolated vertigo is more easily suspected in an elderly patients with hypertension, hyperlipidemia or cardiac disease, but can be easily missed in younger patients without vascular risk factors. The diagnosis in these patients becomes even more difficult since between the TIAs the neurological examination and neuroimaging (such as brain CT scan or MRI) might be normal. It has been demonstrated that in a small group of patients (six patients) with isolated vertigo as a manifestation of vertebrobasilar ischemia, abnormal patterns on MRA, consisting of focal basilar stenosis or widespread vertebrobasilar flow, can be found [5]. However, a routine referral of patients with vertigo for MRA or conventional angiography can be certainly not justified. There are several clinical situations where a therapeutic trial can help in the diagnosis, as in patients with vestibular paroxysmia where the attacks improve after administration of antiepileptics or in patients with vestibular migraine where the vertigo resolves under prophylactic treatment for migraine [10]. Also patients with incipient Meniere's disease where the diagnosis is not clarified, get relief by treatment with betahistidine or diuretics. In a similar vein, patients with TIA presenting as monosymptomatic vertigo might benefit from antiplatelets or, in selected cases, anticoagulation.

We would like to present our experience with patients with isolated vertigo where a vascular origin was suspected on clinical grounds and where antiplatelet or anticoagulation therapy was started.

Methods: We retrospectively reviewed the clinical records of patients with vertebrobasilar attacks who were referred to our Dizziness Clinic during the years 1999 2009. Monosymptomatic patients with episodes of vertigo, unsteadiness and/or vomiting were selected. Their demographic data and clinical findings were recorded. The treatment response to aspirin or other antiplatelet therapy was analyzed. A part of patients has been reported in Aspirin and Health Research Progress, Chapter 4, pp. 5568, 2008, Editor Paul I. Quinn. Reprint permission has been obtained from the publisher.

The study was a retrospective study based on data collection from old medical records and the patients remained anonymous. The collected data included demographic and clinical information about therapy response to a routinely given drug (aspirin) which was not administered for the purpose of the study.
Results (Table 1): Amongst about 150 patients with vertebrobasilar TIA the diagnosis of monosymptomatic vertigo was made in 24 . Their mean age was $67.3 \pm 10$ years (range 46 - 89, median 66.5). Fifteen were men and nine were women.

The diagnosis of vertebrobasilar TIA was based on the history of unprovoked episodes of spontaneous vertigo i.e. the illusion of spinning of the surroundings, accompanied by unsteadiness, in absence of other neurological or ontological symptoms. Eleven patients also had nausea and vomiting. Two patients presented with positional vertigo-vertigo that occurred only in certain positions and persisted as long as the provoking position was maintained. The attacks lasted several hours (mean $13.3 \pm$ 19.3 hours, range 0.5 - 48, mean 2) but in five patients they were of several minutes duration. Seven patients had suffered a single vertigo episode, while in others the vertigo attacks were recurrent.

The presence of vascular risk factors supported the diagnosis: 15 patients had hypertension, five had diabetes mellitus and six had hyperlipidemia. Two patients reported smoking. One patient suffered from ischemic heart disease, four had a history of cardiac arrhythmia and one had a cardiomyopathy. The combination of two or more vascular risk factors was present in 13 individuals. Among four patients with no vascular risk factor in the history two were older than 70 years (age as a vascular risk factor), in one patients aortic atherosclerotic aneurysm and in the other aortic valve vegetations were found subsequently.

All patients underwent a detailed neurotological examination which included examination of eye movements -range, smooth pursuit and saccades, the head-thrust test, head shaking test using Frenzel's glasses, examination of stance and gait and positioning testing. The latter consisted of the Dix-Hallpike test and horizontal canal test. Other cranial nerves and optic fundi, as well as motor, sensory and cerebellar functions were examined. The neurotological examination, between the attacks, was normal in all patients.

A brain CT scan was obtained in 18 and a MRI scan in six patients. Neuroimaging revealed small-vessel disease in the form of white matter disease or lacunar infarcts in eight patients and was normal in all others. Audiometric testing and brainstem evoked auditory potentials were performed to exclude other causes of vertigo. A cardiovascular workup consisted of carotid and vertebral artery duplex studies, an echocardiogram and Holter electrocardiogram. In indicated cases a transeosophageal echocardiogram was performed. A significant right carotid artery stenosis (more than 70\%) was revealed in one and moderate carotid artery stenosis (50\% - 70\%) was found in two patients.

The mean time period from the first episode of vertigo 
Table 1. Clinical characteristics and treatment outcome in patients with TIA presenting as isolated vertigo.

\begin{tabular}{|c|c|c|c|c|c|c|c|c|c|c|c|c|}
\hline $\begin{array}{l}\text { Patient } \\
\text { No. }\end{array}$ & Age & Sex & $\begin{array}{l}\text { Presenting } \\
\text { symptoms }\end{array}$ & $\begin{array}{c}\text { Duration } \\
\text { of attacks } \\
\text { (in hours) }\end{array}$ & $\begin{array}{c}\text { Number } \\
\text { of attacks }\end{array}$ & $\begin{array}{c}\text { Time since } \\
\text { 1st attack to } \\
\text { treatment } \\
\text { (months) }\end{array}$ & $\begin{array}{l}\text { Vascular risk } \\
\text { factors* }\end{array}$ & $\begin{array}{l}\text { Neuro-imaging } \\
\text { (CT) }\end{array}$ & $\begin{array}{l}\text { Treatment } \\
\text { (mg/day) }\end{array}$ & $\begin{array}{c}\text { Out- } \\
\text { come }^{* *}\end{array}$ & $\begin{array}{l}\text { Follow } \\
\text { up } \\
\text { (months) }\end{array}$ & Remarks \\
\hline 1 & 66 & $\mathrm{f}$ & vertigo & 48 & 1 & 0.5 & HT, DM & $\begin{array}{l}\text { lacunar infarct in the } \\
\text { basal ganglia }\end{array}$ & $\begin{array}{l}\text { clopidogrel } \\
75\end{array}$ & + & 48 & \\
\hline 2 & 85 & $\mathrm{~m}$ & $\begin{array}{l}\text { vertigo, } \\
\text { vomiting }\end{array}$ & 1.5 & multiple & 12 & HT, IHD, CA & $\begin{array}{l}\text { white matter } \\
\text { disease }\end{array}$ & warfarin & + & 36 & \\
\hline 3 & 67 & $\mathrm{~m}$ & $\begin{array}{l}\text { vertigo, } \\
\text { vomiting }\end{array}$ & 2 & multiple & 12 & HT, CA & $\begin{array}{l}\text { hemispheral lacunar } \\
\text { infarcts (MRI) }\end{array}$ & aspirin 325 & + & 12 & \\
\hline 4 & 69 & $\mathrm{f}$ & vertigo & 3 & multiple & 3 & HT & normal & aspirin 100 & + & 5 & \\
\hline 5 & 70 & $\mathrm{~m}$ & $\begin{array}{l}\text { vertigo, } \\
\text { vomiting }\end{array}$ & 2.5 & 2 & 0.5 & - & normal & aspirin 100 & + & 24 & \\
\hline 6 & 57 & $\mathrm{f}$ & $\begin{array}{l}\text { vertigo, } \\
\text { nausea }\end{array}$ & 8 & 1 & 0.5 & $\begin{array}{c}\text { CA, car- } \\
\text { dio-myopathy }\end{array}$ & normal & aspirin 100 & + & 58 & \\
\hline 7 & 62 & $\mathrm{f}$ & $\begin{array}{l}\text { vertigo, } \\
\text { vomiting }\end{array}$ & 2.5 & multiple & 24 & HT & normal (MRI) & aspirin 325 & - & 20 & \\
\hline 8 & 66 & $\mathrm{~m}$ & vertigo & 0.5 & 3 & 6 & HT & normal & $\begin{array}{l}\text { aspirin } 100+ \\
\text { clopidogrel } \\
75\end{array}$ & + & 48 & \\
\hline 9 & 57 & $\mathrm{~m}$ & $\begin{array}{l}\text { positional } \\
\text { vertigo }\end{array}$ & 2 & 3 & 2 & $\begin{array}{l}\text { HT, HL, } \\
\text { severe ICA } \\
\text { stenosis }\end{array}$ & $\begin{array}{l}\text { hemispheral and } \\
\text { pontine lacunar } \\
\text { infarcts (MRI) }\end{array}$ & aspirin 325 & - & 44 & \\
\hline 10 & 65 & $\mathrm{~m}$ & vertigo & 1.75 & 1 & 2 & HT & normal & $\begin{array}{l}\text { clopidogrel } \\
75\end{array}$ & + & 31 & \\
\hline 11 & 78 & $\mathrm{~m}$ & $\begin{array}{l}\text { vertigo, } \\
\text { nausea }\end{array}$ & minutes & 3 & 12 & HT, HL & normal & aspirin 300 & + & 72 & \\
\hline 12 & 77 & $\mathrm{f}$ & $\begin{array}{l}\text { vertigo, } \\
\text { vomiting }\end{array}$ & 0.5 & 1 & 12 & - & normal & aspirin 100 & + & 36 & \\
\hline 13 & 75 & $\mathrm{f}$ & $\begin{array}{l}\text { positional } \\
\text { vertigo }\end{array}$ & minutes & multiple & 1 & HT, DM & normal & - & $\begin{array}{l}\text { cerebellar } \\
\text { infarct }\end{array}$ & 10 & \\
\hline 14 & 46 & $\mathrm{f}$ & vertigo & minutes & multiple & 6 & - & normal & - & $\begin{array}{l}\text { lateral } \\
\text { medullary } \\
\text { infarct }\end{array}$ & $y$ & $\begin{array}{l}\text { aortic valve } \\
\text { vegetations } \\
\text { found }\end{array}$ \\
\hline 15 & 89 & $\mathrm{f}$ & $\begin{array}{l}\text { vertigo, } \\
\text { vomiting }\end{array}$ & 0.5 & 4 & 4 & age & white matter disease & aspirin 100 & + & 7 & \\
\hline 16 & 57 & $\mathrm{~m}$ & $\begin{array}{l}\text { vertigo, } \\
\text { unsteadiness }\end{array}$ & minutes & 1 & 1.5 & $\begin{array}{l}\text { moderate ICA } \\
\text { stenosis }^{* * *}\end{array}$ & normal & aspirin 100 & + & 23 & \\
\hline 17 & 71 & $\mathrm{~m}$ & vertigo & 0.5 & multiple & 6 & HT, HL & normal & aspirin 300 & + & 48 & $\begin{array}{c}4 \text { y later } \\
\text { hemisp TIA }\end{array}$ \\
\hline 18 & 60 & $\mathrm{~m}$ & vertigo & minutes & 3 & 6 & $\begin{array}{l}\text { DM, HL, } \\
\text { smoking }\end{array}$ & normal & aspirin 325 & + & 36 & \\
\hline 19 & 69 & $\mathrm{~m}$ & vertigo & 1.5 & multiple & 3 & HT, DM & normal & aspirin 100 & + & 11 & \\
\hline 20 & 69 & $\mathrm{~m}$ & $\begin{array}{l}\text { vertigo, } \\
\text { vomiting }\end{array}$ & 24 & 1 & 1 & HT, DM, HL & $\begin{array}{l}\text { mild ischemic } \\
\text { changes (MRI) }\end{array}$ & $\begin{array}{c}\text { aspirin }+ \\
\text { dipyridamol }\end{array}$ & + & 26 & $\begin{array}{l}1 \text { m later } \mathrm{l} \mathrm{t} \\
\text { VII palsy }\end{array}$ \\
\hline 21 & 82 & $\mathrm{~m}$ & $\begin{array}{l}\text { vertigo, } \\
\text { unsteadiness }\end{array}$ & 48 & 1 & 3 & HT, CA & $\begin{array}{l}\text { mild ischemic } \\
\text { changes (MRI) }\end{array}$ & warfarin & + & 16 & $\begin{array}{l}1 \mathrm{w} \text { later } \mathrm{l} \mathrm{t} \\
\text { VII palsy }\end{array}$ \\
\hline 22 & 58 & $\mathrm{~m}$ & $\begin{array}{l}\text { vertigo, } \\
\text { vomiting }\end{array}$ & 1 & 2 & 3 & HL, smoker & $\begin{array}{l}\text { mild ischemic } \\
\text { changes (MRI) }\end{array}$ & aspirin 100 & + & 1 & \\
\hline 23 & 61 & $\mathrm{~m}$ & $\begin{array}{l}\text { vertigo, } \\
\text { vomiting }\end{array}$ & 48 & 2 & 1.5 & $\begin{array}{l}\text { moderate ICA } \\
\text { stenosis }\end{array}$ & & $\begin{array}{l}\text { clopidogrel } \\
75\end{array}$ & + & 6 & \\
\hline 24 & 60 & $\mathrm{f}$ & $\begin{array}{l}\text { vertigo, } \\
\text { vomiting }\end{array}$ & 48 & 2 & 3 & - & normal & aspirin 100 & - & 34 & $\begin{array}{l}\text { thoracic } \\
\text { aortic } \\
\text { aneurysm } \\
\text { found later }\end{array}$ \\
\hline
\end{tabular}

*HT: hypertension, DM: diabetes mellitus, CA: cardial arrhythmia, IHD: ischemic heart disease, HL: hyperlipidemia; ${ }^{* *}+:$ attacks stopped, -: unchanged; ${ }^{* * *}$ ICA: internal carotid stenosis severe $>70 \%$, moderate $50 \%-70 \%$; multiple: more than 2 . 
attack until attending the dizziness clinic was $5.2 \pm 5.5$ months (range 0.5 - 24, median 3). The duration of follow up was $27.4 \pm 19$ months (range 1 - 72, median 25).

Antiaggregant therapy with aspirin (100 - $325 \mathrm{mg} /$ daily) was started in 15 patients. Three patients were started on clopidogrel $75 \mathrm{mg}$ daily because of aspirin intolerance. In two patients treated with aspirin prior to the vertigo attacks, clopidogrel and dipyridamol were added. In two patients with atrial fibrillation warfarin was administered and the dosage was adjusted to maintain the INR between 2 - 3 .

In 18 out of 22 treated patients the vertigo ceased completely. The patient treated with aspirin and clopidogrel reported no further attacks, but suffered from a gastrointestinal bleed 3 years after initiation of the treatment. In two patients the diagnosis of vertebrobasilar TIA was initially missed: The first patient (N.13) was a 75-yearold lady with hypertension and diabetes mellitus who reported recurrent episodes of positional vertigo of one month's duration. The diagnosis of benign positional paroxysmal vertigo (BPPV) was suspected. She developed a right anterior cerebellar artery infarct. The other case (N.14) was a 46-year-old, previously healthy woman, who suffered from recurrent attacks of spontaneous vertigo lasting minutes during six months prior to hospitalization. In view of the history of migraine and a normal brain CT scan the diagnosis of migraine-related peripheral vestibular dysfunction was supposed. On the day of admission she had another vertigo attack, this time accompanied by severe unsteadiness, headache, dysphagia and dysarthria. On examination a central type of nystagmus was found, as well as crossed sensory loss for pain and temperature and cerebellar signs on the left. The diagnosis of left lateral medullary infarct was suspected and later confirmed by brain MRI. An echocardiogram and transesophageal echocardiogram revealed aortic valve vegetations with aortic valve insufficiency as the most probable source of an embolus to the medulla. Heparin i.v. and antibiotics were started and the patient was referred for urgent cardiosurgery.

\section{Discussion}

In a previous study, isolated vertigo has been reported in $21 \%$ of patients with vertebrobasilar ischemia which is similar to the rate of $24 \%$ in our study [5]. In this report, episodic vertigo occurred at least four weeks as the only presenting symptoms but late symptoms, such as diplopia, ataxia or quadriparesis, developed later. All patients had either focal/basilar artery stenosis or a widespread slow vertebrobasilar flow on MRA and all but two were treated with warfarin.

Most of our patients suffered recurrent episodes of vertigo that lasted hours. This is in contrast to previous studies which described the episodes of vertebrobasilar TIA presenting with isolated vertigo as being abrupt and of short duration [1-5]. Moreover, in most of our patients the initiation of the vertigo episodes dated several months back, as in the patient with a lateral medullary stroke where the stroke was preceded by multiple spontaneous vertigo episodes of six months duration.

Eighty seven percent of our patients suffered from diseases which predispose to atherosclerosis (diabetes mellitus, hypertension) or which can be a source of emboli to the vertebrobasilar system (cardiac arrhythmias, cardiomyopathy). Neuroradiological evidence of cerebrovascular disease, in the form of lacunar brain infarcts or white matter disease, was found in only one third of patients. The yield could have been probably higher if all patients had a brain MRI instead of CT. Vertebral and carotid artery blood flow studies were not contributory, since in all but three patients they were normal. Studies of intracranial vessels, such as transcranial doppler (TCD), MRA or CT-angiography, might have shown arteriosclerosis of the intracranial vessels and provide an indirect proof for the vascular cause of the symptoms.

In $81 \%$ of patients with vertigo suspected to be of vascular origin the attacks ceased completely after initiation of antiaggregant/anticoagulant therapy. The diagnosis was assumed clinically and therefore our patient sample is most probably not pure and includes patients with vertigo attacks of other than vascular origin such as incipient Meniere's disease or autoimmune inner ear disorders which have a variable clinical cause with unpredictable recurrences. However, the high rate of positive response to antiaggregant/anticoagulant therapy deserves attention and warrants further case controlled studies. The risk-benefit ratio of treatment should also be evaluated but it seems that the benefit outweighs the risk since only one patient in our series had a bleeding as a consequence of combined treatment with aspirin and clopidogrel.

\section{Conclusion}

Despite previous statements, the differential diagnosis of vertigo attack in individuals with vascular risk factors should include vertebrobasilar TIA. In view of lack of a specific test for establishing the diagnosis, antiplatelets/ anticoagulant therapy should be administered on empirical grounds since early therapy can abolish further attacks and prevent a vertebrobasilar stroke.

\section{REFERENCES}

[1] R. W. Baloh, "Vertebrobasilar Insufficiency and Stroke," Otolaryngology Head and Neck Surgery, Vol. 112, No. 1, 1995, pp. 114-117. doi:10.1016/S0194-5998(95)70309-8

[2] C. M. Fisher, "Vertigo in Cerebrovascular Diseases," Archives of Otolaryngology Head Neck Surgery, Vol. 85, No. 5, 1947, pp. 529-534. 
doi:10.1001/archotol.1967.00760040531010

[3] A. Grad and R. W. Baloh, "Vertigo of Vascular Origin. Clinical and Electronystagmographic Features in 84 Cases," Archives of Neurology, Vol. 46, No. 3, 1989, pp. 281-284.

[4] J. G. Oas and R. W. Baloh, "Vertigo and the Anterior Inferior Cerebellar Artery Syndrome,” Neurology, Vol. 42, No. 2, 1992, pp. 2274-2279.

[5] C. R. Gomez, S. Cruz-Flores, M. D. Malkoff, C. M. Sauer and C. M. Burch, "Isolated Vertigo as a Manifestation of Vertebrobasilar Ischemia,” Neurology, Vol. 47, No. 1, 1996, pp. 94-97.

[6] C. Y. Huang and Y. L. Yu, "Small Cerebellar Strokes May Mimic Labyrinthine Lesions,” Journal of Neurology, Neurosurgery \& Psychiatry, Vol. 48, No. 3, 1985, pp. 263265. doi:10.1136/jnnp.48.3.263
[7] T. D. Fife, R. W. Baloh and G. R. Duckwiler, "Isolated Dizziness in Vertebrobasilar Insufficiency: Clinical Features, Angiography, and Follow-Up,” Journal of Stroke and Cerebrovascular Diseases, Vol. 4, No. 1, 1991, pp. 4-12. doi:10.1016/S1052-3057(10)80139-9

[8] G. W. Kim and J. H. Heo, "Vertigo of Cerebrovascular Origin Proven by CT Scan or MRI: Pitfalls in Clinical Differentiation from Vertigo of Aural Origin," Yonsei Medical Journal, Vol. 37, No. 1, 1996, pp. 47-51.

[9] H. Lee, H. A. Yi, Y. W. Cho, C. H. Sohn, G. T. Whitman, S. Ying and R. W. Baloh, "Nodulus infarction Mimicking Acute Peripheral Vestibulopathy,” Neurology, Vol. 60, No. 10, 2003, pp. 1700-1702.

[10] M. Dieterich, "Vaskular Schwindel," Der Nervenarzt, Vol. 73, No. 12, 2002, pp. 1133-1143. doi:10.1007/s00115-002-1454-5 